\title{
GMR
}

\section{ERCC1 C118T polymorphism has predictive value for platinum-based chemotherapy in patients with late-stage bladder cancer}

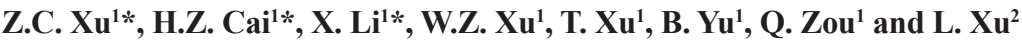 \\ ${ }^{1}$ Department of Urologic Surgery, \\ The Affiliated Cancer Hospital of Jiangsu Province, Nanjing Medical University, \\ Nanjing, China \\ ${ }^{2}$ Department of Thoracic Surgery, \\ The Affiliated Cancer Hospital of Jiangsu Province, Nanjing Medical University, \\ Nanjing, China \\ *These authors contributed equally to this study. \\ Corresponding author: $\mathrm{L}$. Xu \\ E-mail: xulin_surgery@163.com \\ Genet. Mol. Res. 15 (2): gmr.15027801 \\ Received October 8, 2015 \\ Accepted December 23, 2015 \\ Published May 23, 2016 \\ DOI http://dx.doi.org/10.4238/gmr.15027801
}

\begin{abstract}
This study aims to investigate the association between $E R C C 1$ codon $\mathrm{C} 118 \mathrm{~T}$ polymorphism and the response rate of platinumbased chemotherapy in patients with late-stage bladder cancer. A total of 41 eligible patients histologically confirmed as having stage IV muscleinvasive transitional cell carcinoma of the bladder were treated with platinum-based chemotherapy for 2-6 cycles. The genotypes of patients were determined by PCR amplification of genomic DNA followed by restriction enzyme digestion. Positive responses were categorized as complete and partial responses. In addition, progression-free survival (PFS) and overall survival (OS) were also determined as indicators of long-term outcomes. The genotype frequencies of $\mathrm{C} / \mathrm{C}, \mathrm{C} / \mathrm{T}$ and $\mathrm{T} / \mathrm{T}$ genotypes were $56.1,34.1$, and $9.8 \%$, respectively. Positive response was observed in 14 patients $(34.1 \%)$, while 27 patients $(65.9 \%)$ were
\end{abstract}


negative responders. As compared with individuals carrying the $\mathrm{C} / \mathrm{T}$ and $\mathrm{T} / \mathrm{T}$ genotypes, those with the $\mathrm{C} / \mathrm{C}$ genotype had significantly improved short-term treatment responses $(\mathrm{P}=0.018)$. The median PFS of patients carrying the $\mathrm{C} / \mathrm{C}$ genotype was 6.3 months, while that of patients with $\mathrm{C} / \mathrm{T}$ and $\mathrm{T} / \mathrm{T}$ genotypes was 4.2 months $(\mathrm{P}=0.023)$. Moreover, the median OS for patients carrying the $\mathrm{C} / \mathrm{C}$ genotype was also longer as compared with that of patients carrying $\mathrm{C} / \mathrm{T}$ and $\mathrm{T} / \mathrm{T}$ (11.7 months vs 8.5 months, $\mathrm{P}=0.040)$. Our results indicated that the $E R C C 1$ codon 118 polymorphism may have predictive potential for chemotherapy treatment responses in late-stage bladder cancer patients.

Key words: $E R C C 1$; Polymorphism; Bladder cancer; Chemotherapy

\section{INTRODUCTION}

Bladder cancer $(\mathrm{BC})$ is the most common malignancy of the urinary tract, and is the 7th and 17th most common cancer in men and women, respectively (Jemal et al., 2011). Approximately 356,000 new cases and approximately 145,000 deaths are attributed to this disease each year (Ploeg et al., 2009). During the initial diagnosis of BC, approximately $30 \%$ of the cases are diagnosed as muscle-invasive $\mathrm{BC}, 15 \%$ of which are already metastatic (Rosenberg et al., 2005). For patients with late-stage BC, treatments remain a clinical challenge. Cisplatin-containing combination chemotherapy has been the standard treatment for $\mathrm{BC}$ since the late 1980s. Gemcitabine combined with cisplatin (GC) have been used as the standard first-line regime, and has been shown to improve the overall survival and quality of life of BC patients. However, less than $50 \%$ patients were found to be responsive to chemotherapy (von der Maase et al., 2000). Therefore, it is important to find new biomarkers to accurately predict disease prognosis and patient responses to therapies.

Differential chemotherapy responses and survival rates may be related to an individual's genomic variations, which may influence the expression and/or function of enzymes associated with drug metabolism (Kalikaki et al., 2009). Platinum compounds including cisplatin are heavy metal complexes that form adducts and covalent cross-links between the two DNA strands, thus effectively blocking DNA replication and transcription. Excision repair cross-complementation group 1 (ERCC1), a crucial complex in the nucleotide excision repair (NER) pathways, plays a pivotal role in DNA damage recognition and removal of damaged nucleotides (van Duin et al., 1987). Altered expression of the ERCC1 gene can influence DNA repair (Furuta et al., 2002), and its protein level correlates with sensitivity to platinum and its associated compounds (Scheil-Bertram et al., 2010). It has also been reported that ERCC1 single nucleotide polymorphisms (SNPs) may have an effect on ERCC1 mRNA expression (Yu et al., 2000; Ma et al., 2007).

Recently, ERCC1 polymorphisms were found to be associated with colorectal cancer risk (Yang et al., 2015). In addition, expression of ERCC1 could predict the clinical outcomes of non-small cell lung cancer patients receiving platinum-based chemotherapy (Wang et al., 2014). Furthermore, several SNPs of ERCC1, especially ERCC1 codon C118T, have been suggested to be important for predicting the efficacy of platinum-based chemotherapy in cancers. It has been shown that high expression of the $E R C C 1$ gene is associated with poor clinical outcome following cisplatin-based adjuvant chemotherapy for locally advanced BC. However, there has 
been no report on the association between the ERCC1 codon C118T polymorphism and the response rate in $\mathrm{BC}$ patients treated with platinum-based chemotherapy. Therefore, we performed this retrospective study in order to determine whether ERCC1 codon C118T polymorphism can be used as a novel biomarker to predict $\mathrm{BC}$ prognosis and treatment responses.

\section{MATERIAL AND METHODS}

\section{Study subjects}

All patients for the study were recruited from the affiliated Cancer Hospital of Jiangsu Province in China between January 2010 and September 2012. A total of 41 eligible patients were histologically diagnosed with stage IV muscle-invasive transitional cell carcinoma. The disease stages were classified based on the American Joint Committee on Cancer tumor-nodemetastasis (TNM) classification. Tumor sizes were measured using computed tomography or magnetic resonance imaging. All patients had a Karnofsky Performance Score of not less than 70 , and showed normal electrocardiograms. In addition, all patients had normal blood chemistries and hepatic and renal function at the beginning of the treatment. Written informed consent was given by all the subjects prior to the blood collection $(5 \mathrm{~mL})$. The study was approved by the Institutional Review Board of the Nanjing Medical University, Nanjing, China.

\section{Chemotherapy regime and evaluation of therapeutic effect}

All patients were treated with gemcitabine + cisplatin $(\mathrm{GC})$. Patients were administered gemcitabine $\left(1000 \mathrm{mg} / \mathrm{m}^{2}\right)$ on days 1 and 8 , and $\mathrm{GC}\left(70 \mathrm{mg} / \mathrm{m}^{2}\right)$ was given on day 2 in the 3 -week treatment cycle. All chemotherapeutic drugs were administered intravenously, and all patients received 2-6 cycles. Patient responses to treatment were determined after 2 cycles. Therapeutic effects were evaluated according to the Response Evaluation Criteria in Solid Tumors recommended by the National Cancer Institute (Therasse et al., 2000). The short-term responses were classified into 4 groups: complete response (CR), partial response (PR), stable disease (SD), and progressive disease (PD). CR was defined as the complete disappearance of all measurable tumors with no observed relapse for 4 weeks. PR required at least $30 \%$ reduction in measurable lesions. Patients with SD showed less than a $30 \%$ decrease in tumors or no more than a $20 \%$ increase in the size of measurable lesions. PD was assigned to patients when measurable lesions increased by more than $20 \%$ or new tumor foci were found. CR and PR were considered positive responses, while both SD and PD were considered as negative responses. Patient follow-up was performed every 3 months following chemotherapy as well as by routine phone calls. Progression-free survival (PFS) was calculated from the date when chemotherapy was started until the date of confirmed relapse, and overall survival (OS) was defined as the time between start of chemotherapy and death or date of last follow-up.

\section{DNA collection and genotyping}

Venous blood was collected from all patients, and genomic DNA was extracted according to the manufacturer protocol using the Qiagen blood Mini kit (Qiagen, Hilden, Germany). For genotyping of ERCC1 codon C118T polymorphisms, PCR amplification of genomic DNA was followed by restriction enzyme digestion (PCR-RFLP). The primers 
used were as follows: ERCC1-F, 5'-GCAGAGCTCACCTGAGGAAC-3'; ERCC1-R, 5'-GAGGTGCAAGAAGAGGTGGA-3'. The PCR was performed in a $25-\mu \mathrm{L}$ reaction volume containing $100 \mathrm{ng}$ template DNA, $1 \mu \mathrm{M}$ each primer, $2.5 \mathrm{mM}$ each dNTP, $2.0 \mathrm{mM}$ $\mathrm{MgCl}_{2}$, and $1.0 \mathrm{IU}$ Taq polymerase with $10 \mathrm{X}$ buffer (TaKaRa, Japan). PCR was carried out in a T Profession thermocycler (Biometra, Göttingen, Germany) with the following cycling parameters: initial denaturation at $95^{\circ} \mathrm{C}$ for $5 \mathrm{~min} ; 35$ cycles of $45 \mathrm{~s}$ at $95^{\circ} \mathrm{C}, 45 \mathrm{~s}$ at $65^{\circ} \mathrm{C}$, and $45 \mathrm{~s}$ at $72^{\circ} \mathrm{C}$; and final extension at $72^{\circ} \mathrm{C}$ for $7 \mathrm{~min}$. PCR products were digested overnight with 5 IU BsrDI enzyme (TaKaRa, Japan). DNA fragments were run on a 2\% agarose gel stained with ethidium bromide. For the ERCCl gene, the three possible genotypes were defined by distinct banding patterns: homozygous CC genotype corresponded to a $208 \mathrm{bp}$ band, heterozygous CT genotype corresponded to 2 bands at 208 and $128 \mathrm{bp}$, and homozygous TT genotype corresponded to a $218 \mathrm{bp}$ band.

\section{Statistical analysis}

All statistical analyzes were performed using the SPSS software (version 16.0; SPSS Inc., USA). The correlations between genotype frequencies, clinicopathological features, and therapeutic responses were assessed by $\chi^{2}$ tests. PFS and OS survival curves were plotted using the Kaplan-Meier method and were verified using the log-rank test. Cox proportional hazards regression analysis was used to estimate the hazard ratios (HRs) and 95\% confidence intervals (CIs) in order to evaluate the overall relative risk of relapse and death associated with clinicopathological features and $E R C C 1$ genotype. All statistics were two-sided, and $\mathrm{P}<0.05$ was considered to be statistically significant.

\section{RESULTS}

\section{Patient characteristics}

We studied 41 pathologically verified $\mathrm{BC}$ patients (median age $=65$ year). All cases were confirmed as muscle-invasive urothelial carcinoma by pathologists; $47.5 \%$ of the cases were low-grade, and the rest were high-grade. All the patients were at stage IV of the disease, $26.8 \%$ of which were locally advanced (regional lymph node metastasis without distant metastasis), while the remaining $73.2 \%$ were metastatic. We administered 2 cycles of GC chemotherapy to 28 patients, and the remaining 13 patients received at least 2 cycles of chemotherapy (but no more than 6 cycles). Of the 41 patients enrolled in this study with BC, the genotype frequencies for the ERCC1 codon 118 polymorphisms $\mathrm{C} / \mathrm{C}, \mathrm{C} / \mathrm{T}$, and $\mathrm{T} / \mathrm{T}$, were $56.1 \%(23 / 41), 34.1 \%(14 / 41)$, and $9.8 \%$ (4/41), respectively. The clinical characteristics of $\mathrm{BC}$ patients are presented in Table 1 .

\section{Relationship between short-term treatment responses and patient characteristics}

In our study, positive responses to treatment were observed in 14 patients $(34.1 \%)$, while negative responses occurred in 27 patients $(65.9 \%)$. The distribution of distinct clinicopathologic features such as gender, age, pathology, stage, and cycles of chemotherapy to short-term treatment responses was evaluated. As shown in Table 1, locally advanced cases (any T, N1-3, M0) were found to be more responsive to chemotherapy as compared with 
metastatic cases (any T, any N, M1) $(\mathrm{P}=0.018)$. In addition, we found that patients carrying the $E R C C 1$ codon $118 \mathrm{C} / \mathrm{C}$ have significantly better short-term treatment responses to platinumbased chemotherapy as compared to those carrying the $\mathrm{C} / \mathrm{T}$ and $\mathrm{T} / \mathrm{T}$ polymorphisms $(\mathrm{P}=0.016)$.

\section{Influence of clinicopathological features and ERCC1 C118T polymorphisms on PFS and OS}

As shown in Table 1, patients with low-grade urothelial carcinoma have longer median PFS and OS as compared with those with high-grade carcinoma $(\mathrm{P}<0.05)$. Consistent with results for the association of $E R C C 1 \mathrm{C} 118 \mathrm{~T}$ polymorphism with short-term treatment responses to platinum-based chemotherapy, the $\mathrm{C} / \mathrm{C}$ genotype was also correlated with improved longterm survival. The median PFS for patients carrying the $\mathrm{C} / \mathrm{C}$ genotype was 6.3 months, while that for patients with $\mathrm{C} / \mathrm{T}$ and $\mathrm{T} / \mathrm{T}$ genotypes was 4.2 months $(\mathrm{P}=0.023)$ (Figure 1). Moreover, the median OS for patients carrying the $\mathrm{C} / \mathrm{C}$ genotype was also longer as compared with those carrying $\mathrm{C} / \mathrm{T}$ and $\mathrm{T} / \mathrm{T}(11.7$ months vs 8.5 months, $\mathrm{P}=0.040)$ (Figure 2).

Table 1. Distribution of selected variables in the cases.

\begin{tabular}{|c|c|c|c|c|c|c|c|c|}
\hline \multirow[t]{2}{*}{ Variables } & \multirow[t]{2}{*}{ Cases $[\mathrm{N}(\%)]$} & \multicolumn{2}{|c|}{ Response } & \multirow[t]{2}{*}{ P value } & \multirow[t]{2}{*}{$\mathrm{PFS}^{\mathrm{a}}$} & \multirow[t]{2}{*}{ P value } & \multirow[t]{2}{*}{$\mathrm{OS}^{\mathrm{a}}$} & \multirow[t]{2}{*}{$\mathrm{P}$ value } \\
\hline & & Positive & Negative & & & & & \\
\hline Age (means \pm SD) & $63.6 \pm 7.3$ & & & & & & & \\
\hline$<64$ & $21(51.2)$ & 5 & 16 & 0.271 & 69.1 & 0.146 & 12.9 & 0.638 \\
\hline$\geq 64$ & $20(48.8)$ & 9 & 11 & & 68.5 & & 13.1 & \\
\hline \multicolumn{9}{|l|}{ Gender } \\
\hline Male & 34 (82.9) & 12 & 22 & 0.924 & 7.4 & 0.302 & 11.8 & 0.978 \\
\hline Female & $7(17.1)$ & 2 & 5 & & 9.1 & & 12.7 & \\
\hline \multicolumn{9}{|l|}{ Clinical stage } \\
\hline IV (any T, N1-3, M0) & $10(26.8)$ & 7 & 3 & 0.018 & & & & \\
\hline IV (any T, any N, M1) & $31(73.2)$ & 7 & 24 & & & & & \\
\hline \multicolumn{9}{|l|}{ Chemotherapy cycles } \\
\hline 2 & $28(31.7)$ & 12 & 16 & 0.170 & & & & \\
\hline$\geq 2$ & $13(68.3)$ & 2 & 11 & & & & & \\
\hline \multicolumn{9}{|l|}{ Pathology } \\
\hline Low-grade & $19(47.5)$ & 8 & 11 & 0.504 & 12.3 & $<0.001$ & 17.4 & $<0.001$ \\
\hline High-grade & $22(52.5)$ & 6 & 16 & & 4.8 & & 8.3 & \\
\hline \multicolumn{9}{|c|}{ ERCCl codon 118 genotype } \\
\hline $\mathrm{T} / \mathrm{T}$ & $4(9.8)$ & 0 & 4 & 0.020 & & & & \\
\hline $\mathrm{C} / \mathrm{T}$ & $14(34.1)$ & 2 & 12 & & & & & \\
\hline $\mathrm{C} / \mathrm{C}$ & $23(56.1)$ & 12 & 11 & & & & & \\
\hline $\mathrm{T} / \mathrm{T}+\mathrm{C} / \mathrm{T}$ & $18(43.9)$ & 2 & 16 & 0.016 & 4 & 0.023 & 8 & 0.040 \\
\hline $\mathrm{C} / \mathrm{C}$ & $23(56.1)$ & 12 & 11 & & 6 & & 11 & \\
\hline \multicolumn{9}{|l|}{ Surgical treatment } \\
\hline Yes & $13(31.7)$ & & & & & & & \\
\hline No & $28(68.3)$ & & & & & & & \\
\hline \multicolumn{9}{|l|}{ Radiotherapy } \\
\hline Yes & $7(17.1)$ & & & & & & & \\
\hline No & $34(82.9)$ & & & & & & & \\
\hline
\end{tabular}

${ }^{a}$ Measured in a month. Significant values are in bold.

In the Cox regression model, the PFS and OS for patients with the $\mathrm{C} / \mathrm{C}$ genotype at ERCC1 codon $118 \mathrm{C} / \mathrm{T}$ were approximately 1.83- and 1.94-fold higher than those with $\mathrm{C} / \mathrm{T}$ and $\mathrm{T} / \mathrm{T}$ genotypes $(\mathrm{P}=0.016, \mathrm{HR}=1.83,95 \% \mathrm{CI}=1.12-2.99 ; \mathrm{P}=0.010, \mathrm{HR}=1.94,95 \% \mathrm{CI}$ $=1.17-3.27)$. Low-grade pathology $(\mathrm{P}=0.002, \mathrm{HR}=8.36,95 \% \mathrm{CI}=2.19-31,87 ; \mathrm{P}=0.038$, $\mathrm{HR}=3.24,95 \% \mathrm{CI}=1.07-9.83)$, localized tumors $(\mathrm{P}=0.002, \mathrm{HR}=5.37,95 \% \mathrm{CI}=1.82-15.81$; 
$\mathrm{P}=0.001, \mathrm{HR}=6.417,95 \% \mathrm{CI}=2.21-18.60)$, and surgery after adjuvant chemotherapy $(\mathrm{P}=$ $0.001, \mathrm{HR}=0.124,95 \% \mathrm{CI}=0.04-0.43 ; \mathrm{P}<0.001, \mathrm{HR}=0.04,95 \% \mathrm{CI}=0.01-0.18)$ were also associated with prolonged patients survival, as indicated by PFS and OS.

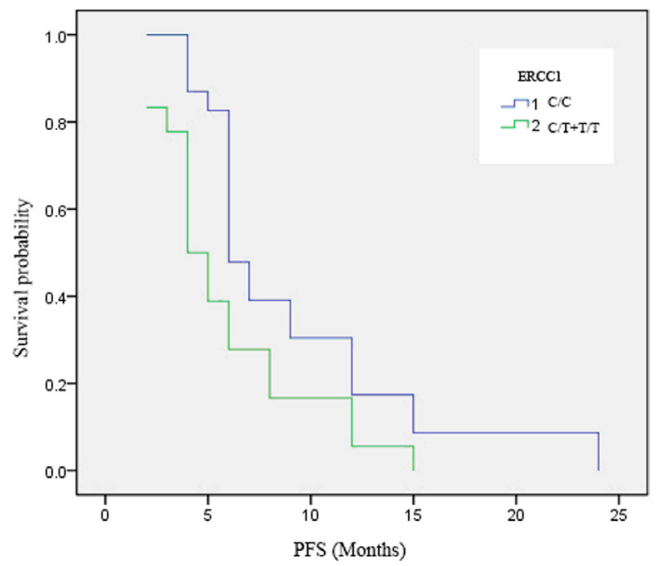

Figure 1. Kaplan-Meier curves of PFS in late-stage $B C$ patients with the genotypes $C / C$ (blue line) or $C / T+T / T$ (green line) and receiving platinum-based chemotherapy $(\mathrm{P}<0.05)$.

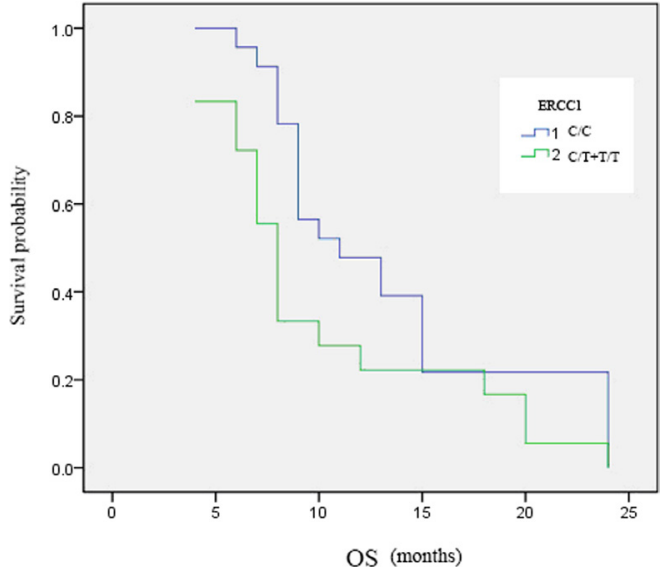

Figure 2. Kaplan-Meier curves of OS in late-stage $\mathrm{BC}$ patients with the genotypes $\mathrm{C} / \mathrm{C}$ (blue line) or $\mathrm{C} / \mathrm{T}+\mathrm{T} / \mathrm{T}$ (green line) and receiving platinum-based chemotherapy $(\mathrm{P}<0.05)$.

\section{DISCUSSION}

Late-stage $\mathrm{BC}$ is a lethal disease with limited therapeutic options. The 5-year survival rate for patients with metastatic BC is only 5\% (Siegel et al., 2014). GC regime have been used as the standard first-line chemotherapy for this disease. However, the response rate is only $49 \%$, and the death rate due to drug toxicity is high (von der Maase et al., 2000). It is therefore important to predict whether a regimen is effective in each patient with $\mathrm{BC}$ before initiation of chemotherapy. Cytostatic drugs including cisplatin and gemcitabin destroy the integrity of genetic information in DNA. Platinum compounds form DNA-platinum adducts, which may 
alter the structure of DNA, leading to apoptosis of cancer cells. However, such changes in the DNA helix can be easily identified and repaired by NER systems, which may play important roles in the ability of tumor cells to resist platinum compounds.

ERCC1 is one of the multifunctional enzymes that belong to the NER complex in cooperation with the xeroderma pigmentosum complementation group F. It is an endonuclease that plays crucial roles in recognition, stabilization, and incision of cisplatin-induced DNA adducts (Simon et al., 2007). The predictive value of ERCC1 expression in platinum-based chemotherapy responses has been reported in various cancers such as non-small cell cancer, ovarian cancer, and cervical cancer, as well as BC (Dabholkar et al., 1994; Kong et al., 2006; Bellmunt et al., 2007; Chen et al., 2010; Hoffmann et al., 2010; Okuda et al., 2011; Park et al., 2011; Cheng et al., 2012; Lv et al., 2014). A systemic review published in 2012 further confirmed the predictive value of ERCC codon C118T polymorphism in advanced colorectal patients treated with platinum-based chemotherapy in the Asian population. This recent meta-analysis involving 356 advanced $\mathrm{BC}$ patients has provided evidence that low/negative expression of $E R C C 1$ is associated with higher objective responses, median progression-free survival, and median OS during platinum-based chemotherapy. Therefore, we proposed that ERCC1 may be a suitable marker of prognosis and sensitivity to platinum-based chemotherapy in patients with advanced BC (Lu et al., 2012).

Genetic polymorphism may affect structure, function, stability, and folding of proteins. Polymorphism in the ERCCl genes could also affect its expression, which may influence the chemotherapy responses in various cancers. A study by Cheng et al. (2012) reported that the $\mathrm{C} 118 \mathrm{~T}$ polymorphism of ERCC1 is associated with patient responses to cisplatin-based chemotherapy in late-stage non-small cell lung cancer. The response rate of patients carrying an $E R C C 1$ codon $118 \mathrm{C} / \mathrm{C}$ allele was more than two-fold higher as compared with that of patients with either the $\mathrm{C} / \mathrm{T}$ or $\mathrm{T} / \mathrm{T}$ genotype. In contrast, Moxley et al. (2013) found that polymorphisms of $E R C C 1$ codon 118 were not associated with clinical responses or survival to platinum-based chemotherapy in advanced epithelial ovarian cancer. To date, no relevant report regarding the association between ERCC1 codon 118 polymorphism and treatment responses in $\mathrm{BC}$ patients has been generated. Results from our current study revealed that patients with the $\mathrm{C} / \mathrm{C}$ genotype at $E R C C 1$ codon 118 have significantly better short-term treatment responses to platinum-based chemotherapy and prolonged PFS and OS as compared with other genotypes. However, there was a lack of statistical significance in short-term responses between patients carrying the $\mathrm{C} / \mathrm{C}$ genotype and those carrying the $\mathrm{C} / \mathrm{T}$ genotype. This may be due to the limited sample size in our study groups. Using multivariate analysis, ERCC codon $118 \mathrm{C} / \mathrm{T}$ polymorphism was identified as an independent predictor of PFS and OS in late-stage BC patients receiving platinum-based chemotherapy. Furthermore, we demonstrated that tumor stage, pathology, surgery, and $E R C C$ codon were also independent predictors of PFS and OS in late-stage $\mathrm{BC}$ patients receiving platinum-based chemotherapy.

However, the following limitations of our study must be acknowledged. First, this study included only 41 subjects. Second, the study was only conducted in the Asian population. Race may influence the therapeutic significance of the study due to genotype frequencies. Moreover, various factors including stage, pathological differentiation, surgery, and radiology after chemotherapy, as well as supportive care before death may also play important roles in determining the PFS or OS. Thus, more precise and large-scale studies need to be performed in order to verify our results.

In conclusion, we evaluated the effect of the ERCC1 C118T polymorphism on treatment response to platinum-based chemotherapy in 41 late-stage $\mathrm{BC}$ patients. The 
ERCC1 codon $118 \mathrm{C} / \mathrm{C}$ genotype may be of predictive value in individualized chemotherapy for $\mathrm{BC}$ patients.

\section{Conflicts of interest}

The authors declare no conflicts of interest.

\section{ACKNOWLEDGMENTS}

Research supported by the Affiliated Cancer Hospital of Jiangsu Province of Nanjing Medical University, Nanjing, China (\#ZQ 201301 and \#ZQ 201302) and the Nanjing Science and Technology Plan Project (\#201201087).

\section{REFERENCES}

Bellmunt J, Paz-Ares L, Cuello M, Cecere FL, et al.; Spanish Oncology Genitourinary Group (2007). Gene expression of ERCC1 as a novel prognostic marker in advanced bladder cancer patients receiving cisplatin-based chemotherapy. Ann. Oncol. 18: 522-528. http://dx.doi.org/10.1093/annonc/mdl435

Chen S, Zhang J, Wang R, Luo X, et al. (2010). The platinum-based treatments for advanced non-small cell lung cancer, is low/negative ERCC1 expression better than high/positive ERCC1 expression? A meta-analysis. Lung Cancer 70: 63-70. http://dx.doi.org/10.1016/j.lungcan.2010.05.010

Cheng J, Ha M, Wang Y, Sun J, et al. (2012). A C118T polymorphism of ERCC1 and response to cisplatin chemotherapy in patients with late-stage non-small cell lung cancer. J. Cancer Res. Clin. Oncol. 138: 231-238. http://dx.doi. org/10.1007/s00432-011-1090-1

Dabholkar M, Vionnet J, Bostick-Bruton F, Yu JJ, et al. (1994). Messenger RNA levels of XPAC and ERCC1 in ovarian cancer tissue correlate with response to platinum-based chemotherapy. J. Clin. Invest. 94: 703-708. http://dx.doi. org/10.1172/JCI117388

Furuta T, Ueda T, Aune G, Sarasin A, et al. (2002). Transcription-coupled nucleotide excision repair as a determinant of cisplatin sensitivity of human cells. Cancer Res. 62: 4899-4902.

Hoffmann AC, Wild P, Leicht C, Bertz S, et al. (2010). MDR1 and ERCC1 expression predict outcome of patients with locally advanced bladder cancer receiving adjuvant chemotherapy. Neoplasia 12: 628-636.http://dx.doi.org/10.1593/ $\underline{\text { neo. } 10402}$

Jemal A, Bray F, Center MM, Ferlay J, et al. (2011). Global cancer statistics. CA Cancer J. Clin. 61: 69-90. http://dx.doi. org/10.3322/caac. 20107

Kalikaki A, Kanaki M, Vassalou H, Souglakos J, et al. (2009). DNA repair gene polymorphisms predict favorable clinical outcome in advanced non-small-cell lung cancer. Clin. Lung Cancer 10: 118-123. http://dx.doi.org/10.3816/ CLC.2009.n.015

Kong SY, Lee H, Lee ES, Park S, et al. (2006). Serum HER2 as a response indicator to various chemotherapeutic agents in tissue HER2 positive metastatic breast cancer. Cancer Res. Treat. 38: 35-39. http://dx.doi.org/10.4143/ crt.2006.38.1.35

Lu X, Xiao S, Jin C, van der Straaten T, et al. (2012). ERCC1 and XPD/ERCC2 polymorphisms' predictive value of oxaliplatin-based chemotherapies in advanced colorectal cancer has an ethnic discrepancy: a meta-analysis. J. Clin. Lab. Anal. 26: 10-15.http://dx.doi.org/10.1002/jcla.20494

Lv H, Han T, Shi X, Yao Y, et al. (2014). Genetic polymorphism of GSTP1 and ERCC1 correlated with response to platinum-based chemotherapy in non-small cell lung cancer. Med. Oncol. 31: 86. http://dx.doi.org/10.1007/s12032014-0086-5

Ma H, Xu L, Yuan J, Shao M, et al. (2007). Tagging single nucleotide polymorphisms in excision repair crosscomplementing group 1 (ERCC1) and risk of primary lung cancer in a Chinese population. Pharmacogenet. Genomics 17: 417-423. http://dx.doi.org/10.1097/01.fpc.0000239975.77088.17

Moxley KM, Benbrook DM, Queimado L, Zuna RE, et al. (2013). The role of single nucleotide polymorphisms of the ERCC1 and MMS19 genes in predicting platinum-sensitivity, progression-free and overall survival in advanced epithelial ovarian cancer. Gynecol. Oncol. 130: 377-382.http://dx.doi.org/10.1016/j.ygyno.2013.04.054 
Okuda K, Sasaki H, Hikosaka Y, Kawano O, et al. (2011). Excision repair cross complementation group 1 polymorphisms predict overall survival after platinum-based chemotherapy for completely resected non-small-cell lung cancer. $J$. Surg. Res. 168: 206-212. http://dx.doi.org/10.1016/j.jss.2009.09.006

Park JS, Jeon EK, Chun SH, Won HS, et al. (2011). ERCC1 (excision repair cross-complementation group 1) expression as a predictor for response of neoadjuvant chemotherapy for FIGO stage 2B uterine cervix cancer. Gynecol. Oncol. 120: 275-279. http://dx.doi.org/10.1016/j.ygyno.2010.10.034

Ploeg M, Aben KK and Kiemeney LA (2009). The present and future burden of urinary bladder cancer in the world. World J. Urol. 27: 289-293.http://dx.doi.org/10.1007/s00345-009-0383-3

Rosenberg JE, Carroll PR and Small EJ (2005). Update on chemotherapy for advanced bladder cancer. J. Urol. 174: 14-20. http://dx.doi.org/10.1097/01.ju.0000162039.38023.5f

Scheil-Bertram S, Tylus-Schaaf P, du Bois A, Harter P, et al. (2010). Excision repair cross-complementation group 1 protein overexpression as a predictor of poor survival for high-grade serous ovarian adenocarcinoma. Gynecol. Oncol. 119: 325-331.http://dx.doi.org/10.1016/j.ygyno.2010.07.018

Siegel R, Ma J, Zou Z and Jemal A (2014). Cancer statistics, 2014. CA Cancer J. Clin. 64: 9-29. http://dx.doi.org/10.3322/ caac. 21208

Simon GR, Ismail-Khan R and Bepler G (2007). Nuclear excision repair-based personalized therapy for non-small cell lung cancer: from hypothesis to reality. Int. J. Biochem. Cell Biol. 39: 1318-1328. http://dx.doi.org/10.1016/j. biocel.2007.05.006

Therasse P, Arbuck SG, Eisenhauer EA, Wanders J, et al. (2000). New guidelines to evaluate the response to treatment in solid tumors. European Organization for Research and Treatment of Cancer, National Cancer Institute of the United States, National Cancer Institute of Canada. J. Natl. Cancer Inst. 92: 205-216. http://dx.doi.org/10.1093/ inci/92.3.205

van Duin M, Koken MH, van den Tol J, ten Dijke P, et al. (1987). Genomic characterization of the human DNA excision repair gene ERCC-1. Nucleic Acids Res. 15: 9195-9213.http://dx.doi.org/10.1093/nar/15.22.9195

von der Maase H, Hansen SW, Roberts JT, Dogliotti L, et al. (2000). Gemcitabine and cisplatin versus methotrexate, vinblastine, doxorubicin, and cisplatin in advanced or metastatic bladder cancer: results of a large, randomized, multinational, multicenter, phase III study. J. Clin. Oncol. 18: 3068-3077.

Wang TB, Zhang NL, Wang SH, Li HY, et al. (2014). Expression of ERCC1 and BRCA1 predict the clinical outcome of non-small cell lung cancer in patients receiving platinum-based chemotherapy. Genet. Mol. Res. 13: 3704-3710. http://dx.doi.org/10.4238/2014.May.9.15

Yang H, Li G and Li WF (2015). Association between ERCC1 and XPF polymorphisms and risk of colorectal cancer. Genet. Mol. Res. 14: 700-705.http://dx.doi.org/10.4238/2015.January.30.13

Yu JJ, Lee KB, Mu C, Li Q, et al. (2000). Comparison of two human ovarian carcinoma cell lines (A2780/CP70 and MCAS) that are equally resistant to platinum, but differ at codon 118 of the ERCC1 gene. Int. J. Oncol. 16: 555-560. 